\title{
Problem Gambling: An Interplay Between Law and Medicine and A Platform to an Interdisciplinary Approach to This Mental Health Disease
}

\author{
Hugo Luz dos Santos* \\ PhD Researcher at the Faculty of Law of University of Macau, China
}

Submission: July 3, 2018; Published: July 17, 2018

*Corresponding author: : Hugo Luz dos Santos, PhD Researcher at the Faculty of Law of University of Macau, China, Tel: (+853) 65527671 ; Email: hugo.miguel.luz@gmail.com

Abstract

Problem gambling is widely known as a mental health disease and the efforts to curb this deleterious social phenomenon ought not to be spared by Governments worldwide. In this paper we avowedly argue that an interplay between law and medicine and, overarching, an interdisciplinary approach of problem gambling, is the best available option to curtail this heinous mental disease.

Keywords: Responsible Gaming; Problem Gambling; Mental Health Disease; Harm-Minimization Strategies; Macau; Interdisciplinary Approach of Problem Gambling

\section{Introduction}

Gaming and betting contracts are a practical expression of homo ludens: they symbolize a desire for entertainment, a ludic desire. That ludic desire of the player, symbolizing an eminently personal need, does not have enough material foundation to merit the right to legal protection, because it lacks economic interest [1]. This consideration is no small one. Governments worldwide are not keen to legalize the gambling activity. Social costs inextricably linked with gaming leisure industry underpin this widespread hesitation. Efforts concerning the creation of a sound responsible gaming model that strives to achieve the deemed harm-minimization is a definitely the goal that one ought to tirelessly pursue in this realm. This cannot be achieved without an interdisciplinary engagement between the knowledge creators (scholars, researchers, medical doctors) and the end-users (casinos, public entities, lawyers, psychiatrists, whose main purpose is to curb problem gambling).

As far as the aforementioned goes, there are not many papers that proficiently combine the legal side with the other side (medical, psychologic, psychiatric, neurological, sociological, social policy), aiming to curtail the issue of problem gambling. To shape a proper responsible gambling model it is crucially important to address the problem gambling in an interdisciplinary way. Needless to say, this is the main aim of this paper.

\section{Background - What is Problem Gambling?}

First things first. How can one outline an accurate definition of problem gambling or problem gambler? [2] Despite the existence of problem gambling, there have been ongoing difficulties with grasping a widely accepted definition of this mental health disease. Conversely, despite being often used, the legal taxonomy «responsible gambling» and «responsible provision» are also scarcely defined. "Although, differences in definition are quite important because they impact on solutions provided to overcome the problem» [3].

«For instance, the Australian Productivity Commission (1999), included a vast range of definitions of problem gambling that variously emphasized either symptoms (e.g., loss of control, chasing debts) or effects (e.g., disruption and damage to personal, family or work life). One widely accepted definition is that adopted by the Victorian Casino and Gaming Authority (VCGA) which states that problem gambling occurs "where a person's gambling activity gives rise to harm to the individual player, and/or to his or her family, and may extended into the community» [4]. On the other hand, «Problem Gambler», as far as the Canadian doctrine is concerned, is widely carved out as any person whose ability to resist the impulse to gamble has been impaired, or whose gambling has compromised, disrupted, or damaged personal family, or vocational pursuits [5]. 
While gambling may be portrayed by the vast majority of gamblers as a dazzling form of entertainment and an enjoyable leisure pursuit, its very nature means that there are staggering risks involved in this activity [6]. «Problem gambling (PG) behaviours (as a reminder, problem gambling is a mental disease) occur when an individual gamble in a manner that exceeds their means, for money than they can afford and spending excessive time gambling, both which can cause deleterious effects on the lives of the gambler. Such effects may include neglecting family, health, hygiene, and even employment, as well financial obligations, which highlights PG as not only an issue at the individual level, but also for wider society. Indeed, for every PG there is potential for a multitude of individuals to be negatively impacted» [7].

\section{Background - Problem Gambling, an Overall Shift of Perspective in Relation to Research and Theory?}

«Over the last 15 years or so, the field of responsible gambling (RG) has developed from a basic interest in minimising gambling problems, to a fast-growing field of research, theory, and practice covering all aspects of the gambling experience. Even in the recent past, RG was typically the remit of perhaps one or two individuals in an organisation, maybe just a minor part of the primary role. However, over the last few years and in many gaming companies, RG has become a concept embraced at all levels from the CEO down to the point-of-sale retailer, and all those in between. Whilst some of this focus has been driven through regulatory policy and an increased awareness of problem gambling across many jurisdictions, much of the interest stems from a realisation that problem-free players make for a better business. That is, long term customers are going to be those who continue to play, without problems, primarily for reasons of leisure. In short, proactive gaming companies have developed socially responsible business models, that are based on increasing the number of moderate-spending, long-term repeat customers and, that strive to avoid custom from players with gambling problems» [8].

The burgeoning growth of Responsible Gaming practice has been accompanied by an overall shift of perspective in relation to research and theory. «Previously, RG was largely influenced by a view of gambling problems that primarily adopted a medical and/or disease model, with little control or power attributed to those that were most negatively affected. However, increasing support for individual autonomy has become the main issue. This position was outlined in detail by the «Reno Model» [9] which argues that responsible gambling should be based upon two fundamental principles: « (1) decisions to gamble reside with individual and represent a choice, and (2) in order to make good decisions, individuals need to be well informed. This shift in perspective also reflects wider social and cultural changes that have seen more of an emphasis on the importance of consumers making informed purchase choices across a variety of products and services. On the other hand, technological developments have become a driving force, for both the design of games and gambling environments, as well as for tools and services that can assist players to play responsibly» [10].

However, whilst there has been a significant development in research and technological breakthroughs in the Responsible Gaming realm, the translation of valid research into wide-spread practice has sometimes been slower to take effect than initially expected [11].

This portrays a huge gap between the above-mentioned knowledge creators and end-users. This gap surely needs to be bridged. But how?

By engaging in an interdisciplinary path that ought to connect both sides of the gambling industry (medical doctors, gambling leisure industry, lawyers) that would significantly boost the benefits of the global innovation in gaming leisure industry. There is no other way. This particular issue will be addressed later and its concretes features will be also thoroughly carved out.

\section{Background - Problem Gambling as a Repository of In- terdisciplinary Contributes: The Cardinal Importance of Empirical Evidence in the Context of Electronic Gambling Machines (EGMs)}

Electronic Gambling Machines (EGMs) represent a sweeping part of the gambling leisure industry. It is widely accepted that EGMs are the core of gambling leisure industry, except in the casinos of Macau, where the table games, namely the Baccarat, heavily outweigh EGMs. That's the reason why Knowledge Creators focus have been driven towards the empirical evidence for the differential impact of gambling outcome on behaviour in electronic gambling [12]. The research undertaken in this specific field has achieved a major breakthrough: EGM's are the realm of addictive patterns of gambling behaviour as they enhance the illusion of control of the players about the outcome of the game. Furthermore, EGM's are markedly the domain of the loss-chasing behaviour, the core characteristic of Problem Gambling, which can be thoroughly explained because:

«§ Approximately $13 \%$ of EGM gamblers meet diagnostic criteria for problem gambling (PG) which is one of the highest rates of among all other forms of gambling. EGMs are interactive, computerised gambling platforms found in many licensed betting offices, casinos, and other leisure facilities.

$\S$ They adopt variable ratio schedules of reinforcement that subject a player to addictive patterns of gambling behaviour. EGMs have been shown to instil and maintain irrational and superstitious beliefs, as well as distort concepts of randomness and probability that can contribute to illusions of control. Such features may act in maintain or indeed contribute to the onset of PG behaviours. § In addition, EGMs offer high maximum stake and prize sizes, where an individual can bet up to $£ 100$ on a gambling event and win jackpots equalling $£ 500$ and the fact that accessibility of EGMs are abundant on the high-street, means even inexperienced and leisure gamblers are at risk of 
increased rate and volume of loss, irrespective of whether they would be classed as PG or not. A rapid speed of play provided by EGMs offer fewer opportunities between bets to break trancelike dissociative states gamblers experience, as well as less time to consider one's decisions in an informed and controlled manner.

$\S$ The rapid event cycle in EGM play also allows for a high rate and volume of loss, which is allowed to further exacerbate if ones engage in loss-chasing behaviour - as stated above, a core characteristic of PG. Loss chasing may not however, be limited to PGs, and there is potential for the fast-paced characteristic of EGM play to negatively impact on» [13]. In this regard, a recent research (conducted by renowned scientists) has investigated how these EGM characteristics interact with winning and losing outcomes and the resulting gambling behaviour, «as there is wide body of evidence outside of gambling research that suggests gains and losses have an asymmetrical impact on affect and arousal, as well as cognitive capacity and decision makingessential components to controlled and rational gambling decisions [14].

Conversely, losses squarely compared to the bulk of wins, have a larger effect on physiological arousal. Hochman and Yechiam (2011) reported significantly larger pupil diameter and increased heart beat in response to losses compared to equivalent sized wins» [15]. On another hand, if losses lead to a greater increase in psychological arousal, this may result in the gambler's optimal level of arousal being surpassed, which may be detrimental to rational decision making (crucially important when it comes to cease immediately the gambling endeavours) and lead to a loss of control during gambling, «where the fastpaced and high stakes features of EGM play may exacerbate the harm caused by a loss of control» [16].

Having this body of evidence very firmly in mind, it is very important to implement strategies that enable the gambler to remain in control during the gambling session so that gamblingrelated decision are made in a rational manner. Moreover, that assortment of measures embodies the deemed harmminimisation strategies that the legal side of gaming leisure industry should not forsake.

\section{Background - The Importance of Empirical Evidence in the Context of Electronic Gambling Machines (EGMs) and The Harm Minimisation Strategies: The Pop-Up Messages and The Personalised Feedback}

If wins and losses do indeed result in an asymmetrical impact on a gambler's behaviour during EGM gambling, it is important to implement harm minimisation strategies in a timely manner before harmful behaviour augment or escalate. As a consequence, prior to the implementation of any harm minimisation strategies whatsoever there is a major paradigm shift yet to be undertaken: the problem gambling should be approached in a proactive manner rather than a purely reactive one. Meaning, knowledge creators (medical doctors and scientists) and end-users (gaming leisure industry, governments, lawyers) ought to synergetically contribute to the creation of healthy gambling environments in a timely manner.

Alongside the technological developments, research into cognitive psychology of gambling has shown that irrational gambling-related cognitions and misunderstandings inextricably connected to randomness and probabilities represent some of the key ingredients contributing to the initiation and maintenance of problem gambling in general, and in electronic (or online) gambling specifically [17]. «More importantly, it has been shown that problematic gambling behaviour can be decreased in response to cognitive-behavioural therapy and other cognitive interventions. As a consequence, some organisations and gaming operators are beginning to offer players information about common gambling myths and erroneous beliefs. Furthermore, players can now access general advice on healthy and responsible gambling» [18].

«A small body of empirical research has shown that educational programs about erroneous beliefs can successfully help change the targeted cognitions. For instance, Wohl developed an animation-based educational video regarding the function of slot machines, their results demonstrated that the animation was effective in promoting responsible play as demonstrated by those viewing the video staying within their pre-set limits. The study also showed that animated educational information on slot machines can be an effective to increase user adherence to pre-set limits» [19].

Research conducted in this realm have also shown that the way the information is presented to problem gambler has a significant impact. Several studies have duly investigated the effects of interactive pop-up messages during gambling sessions either taken online or in a simple brick-and-mortar casino. Static (and colourless) messages do not appear to be as effective, whereas interactive pop-up messages and «attractive and coloured» (say animated) information can thoroughly quash both irrational beliefs and behavior [20]. Stewart and Wohl (2013) highlighted that gamblers who have received a monetary limit pop-up reminder were more prone to adhere to monetary limits than participants who did not [21].

Increasingly arising on the horizon of the gambling field is the personalised feedback, developed for responsible gambling purposes. In sum, personalised feedback is a behavioural tracking tool, for responsible gambling purposes. There are several programs that constitute a striking example of it, such as Playscan, mentor, Bet Buddy [22]. Eulogized scholars emphasized that gamblers receiving carefully tailored feedback about their online gambling behaviour are far more prone to swiftly alter their gambling behaviour (as gauged by the amount of time and money spent gambling online or in a brick-and-mortar casino) compared to those who do not receive a tailored feedback [23].

«A recent study investigated the behavioural change in 279 online gamblers that received personalized feedback after they had signed up to a voluntary service (i.e. mentor) at a European 
online gaming website. Those signing up to use the personalized feedback system were compared with 65, 423 matched controls. The preliminary results of that study show that personalized behavioural feedback within a motivational framework appears to be an effective way of changing gambling behaviour in a positive way (i.e., players significantly reduced the amount of time and/or money they spent gambling after receiving personalized feedback). For instance, if a player significantly increases the amount of money they have deposited over a half year time period, they received the following message: "Over the last 6 months the amount of money deposited into your account has increased. Are you spending more money than you intended? You can check the account you have spent gambling on your account page and use our helpful tools to set a daily/ weekly/monthly limit» [24].

The aforementioned example conspicuously portrays that the messages are non-confrontational, attractive, colorful, personal, and motivational. Additionally, the often-emphasized interactive aspect was taken into account through the use of a pop-up window that has been carved out into the casino operator's gambling site [25]. Overall, the personalization approaches outlined above strive to significantly alter a person's behaviour via behavioural feedback. Such approaches are underpinned on both the "Stages of Change"» model (Prochaska \& DiClemente, 1983) and «motivational interviewing». Specifically asserted the paramount importance of carefully tailored information. In their study they have summarized a vast array of motivational psychology literature to develop a motivational framework based on the Transtheoretical (i.e. States of Behaviour Change), «which states that individuals attempting to change their behaviour in some way go through a series of stages (i.e., pre-contemplation, contemplation, preparation, action, maintenance, and relapse)» [26]. For each stage, they highlighted the motivational goal (s), and recommendation (s) as to how technologies can motivate sustainable energy usage behaviours by people [27]. In sum, behavioural feedback systems enable an optimistic approach of responsible gambling, as they achieve the targeted goal of helping the players sensibly limit the amount of time and money spent gambling [28].

\section{Discussion}

The implementation of a responsible gaming model does not override an interdisciplinary approach. Quite the opposite, the foundation of a proper and sound responsible gaming model cannot be successfully applied without an interdisciplinary approach. Conversely, in order to embrace such a challenge, a collaborative approach between the knowledge creators (e.g., researchers, medical doctors and academics who effortlessly study the social and medical phenomenon of problem gambling) and end-users [29] (e.g., policy makers, lawyers, gambling industry, regulators, gamblers) is now needed more than ever. A collaborative problem-solving between knowledge creators and end-users ought to be based not only in a science-based empirical approach, as emphasized by the Reno Model, but be shaped through linkage and exchange of knowledge between both sides of gaming leisure industry.

As far as an interdisciplinary approach goes, mutual learning in the gaming industry requires the input of a wide range of stakeholders, as the aforesaid mutual learning has multiple stages such as planning, producing, and applying existing empirical research, and its concrete implementation in practice should not disregard the input of any the end-users or decision makers. An interdisciplinary approach of responsible gaming is a two-way street: researchers produce and gather empirical research and decision makers tend to apply existing or new research in decision-making. Researchers do not successfully transfer their empirical findings without the input of the decision makers; conversely, decision makers cannot benefit from an evidence-into-practice approach if they not successfully engage with the researchers.

An effective knowledge exchange involves, oftentimes (if not always) the interaction of both sides of the gambling industry aimed at accelerating the benefits of global innovation in this realm. Therefore, knowledge creators and decision makers, as they are planted itself squarely in the middle of the gambling industry, play a pivotal role both in the creation and implementation of harm minimizing strategies and, ultimately, in the construction of a functional problem gambling model.

Because of that they are the key players of the process of taking knowledge and converting it into practice; they are the protagonists of a strategic framework that intends to bridge the gap between theory and practice.

The guidelines for the implementation of an interdisciplinary approach of responsible gaming, can be summarized as follows:

a) The deemed Knowledge Exchange (KE) is a process of taking knowledge and converting it into practice;

b) $\mathrm{KE}$ is a form of interdisciplinary engagement between the knowledge creators and decision makers;

c) To ensure mutual learning, knowledge creators and decision makers should arrange regular meetings and issue joint statements about the major priorities of problem gambling;

d) Knowledge creators and end-users should provide guidelines and recommendations in implementing harm minimization strategies;

e) The creation of a task-force of specialists in psychology, psychiatry, sociology, law, that should jointly operate inside the casino facilities;

f) This task-force should be primarily responsible for the implementation of harm minimization strategies and complementarily should be also responsible for training the casino staff, as far as spotting, tracking down, identifying and handling the problem gamblers is concerned; 
g) The needs of the end-users should be timely identified by the knowledge creators;

h) To facilitate the aforementioned goal, an atmosphere of trust between the knowledge creators and the end-users is needed;

i) To facilitate that reciprocal approach, regular briefings should be held in order to discuss preliminary results of the implementation of harm-minimization strategies, such as the aforesaid, personalized feedback, loss-limits, win limits, pop-up messages;

j) The communication channel between the researchers and the end-users should always be open, as their relationship should be strengthened through linkage, exchange and joint production;

k) The public entities, or governments, should play a pivotal role as well in establishing priorities, preferences, and goals related with the problem gambling;

l) Moreover, governments should create joint structures that, symbiotically, address the issue of problem gambling;

m) Those joint government structures should have an interdependent relationship, and they should hold meetings and briefings in a regular basis with the casino operators and their interdisciplinary teams;

n) In a regular basis, that joint structures should issue joint guidelines, and should issue joint statements in which they set up harm-minimization strategies to curb problem gambling;

o) Governments who depends heavily on the gaming revenue, for instance Macau, should take the problem gaming seriously;

p) As a consequence, a responsible gaming model should be embraced by the government of Macau, and its focus should be geared not only towards the problem gamblers but, likewise, the positive players, those who just play for fun - in the long run, those are the ones that will keep going to the casinos and not the problem gamblers;

q) Therefore, positive play should be, more than ever, an axiom that the government of Macau should take into account.

r) Focus groups constituted by decision makers from the casino industry and the problem gamblers should take place in a regular basis, in order to assess and appraise ongoing harm-minimization strategies.

s) Problem gamblers input should be taken into account; as far as setting up feasible responsible gaming features, their insight is invaluable.

t) Problem gamblers family should also participate in the process of creation of harm-minimization strategies - they are the core of the personal structure of the problem gambler, and they are the ones who can provide the muchneeded guidance and support throughout the whole process of dealing with the problem gambling.

\section{Conclusion}

Problem Gambling is now so ingrained in the culture of gaming industry as a whole that it will not cease to be a part of service industries anytime in the foreseeable future. For this very reason, an interdisciplinary approach to problem gambling poses a considerable challenge to the casino industry as a whole. For the sake of long-term sustainability of gaming industry as a whole, such a challenge should be timely embraced.

\section{References}

1. Hugo Luz Dos Santos (2015) Contracts for Gaming and Betting in the Casinos in the Special Administrative Region of Macau and the Credit for Gaming: The Issue for "Walking". Gaming Law Review and Economics 19(8): 582.

2. Hugo Luz Dos Santos (2016) Gaming Legal Framework in Macau, Sar: An overview, pp. 18.

3. Helen Breen, Jeremy Buultjens, Nerilee Hing (2005) The Responsible Gaming Code in Queensland, Australia: Implementation and Venue Assessment. UNLV Gaming Research \& Review Journal 9(1): 44.

4. Breen, Buultjens, Hing, p. 44.

5. William V Sasso, Jasminka Kalajdzic (2006) Do Ontario and Its Gaming Venues Owe a Duty of Care to Problem Gamblers? In Gaming Law Review and Economics (GLR\&E) 10(6): 552.

6. Breen, Buultjens, Hing, p. 44.

7. Andrew Harris, Adrian Parke (2015) Empirical evidence for the differential impact of gambling outcome on behavior in electronic gambling: Implications for harm-minimization strategies. Responsible Gaming Review 1(2): 10.

8. Richard Wood, Mark D Griffiths (2014) Putting responsible gambling, theory and research into pratice: Introducing the Responsible Gambling Review. Responsible Gambling Review 1: 1-5.

9. A Blaszczynski, R Ladocoeur, Hj Shaffer (2004) A science-based framework for responsible gambling: The Reno model. Journal of Gambling Studies 20(3): 301-317.

10. Richard Wood, Mark D Griffiths, p. 2.

11. Richard Wood, Mark D Griffiths (2014) Putting responsible gambling, theory and research into pratice: Introducing the Responsible Gambling Review. Responsible Gambling Review 1: 1-5.

12. Hugo Luz Dos Santos (2016) Responsible Gaming in Indian Country. American Gaming Lawyer International Masters of Gaming Law, p. 1.

13. Andrew Harris, Adrian Parke (2015) Empirical evidence for the differential impact of gambling outcome on behavior in electronic gambling: Implications for harm-minimization strategies. Responsible Gaming Review 1(2): 10.

14. Andrew Harris, Adrian Parke, p. 10-11.

15. Andrew Harris, Adrian Parke, p. 12.

16. Andrew Harris, Adrian Parke, p. 12.

17. Michael Auer, Mark D Griffths (2014) Personalised feedback in the promotion of responsible gambling: A brief overview. Responsible Gaming Review 1(1): 28.

18. Michael Auer, Mark D Griffths p. 28. 
19. Michael Auer, Mark D Griffths (2014) Personalised feedback in the promotion of responsible gambling: A brief overview. Responsible Gaming Review 1(1): 28.

20. Michael Auer, Mark D Griffths p. 28.

21. Michael Auer, Mark D Griffths p. 28.

22. Michael Auer, Mark D Griffths p. 28.

23. Michael Auer, Alan Litler, Mark D Griffiths (2015) Legal Aspects of Responsible Gaming Pre-commitment and Personal Feedback Initiatives. Gaming Law Review and Economics (GLRE) 19(6): 444456.
24. Michael Auer, Mark D Griffths, p. 31.

25. Michael Auer, Mark D Griffths, p. 31.

26. Michael Auer, Mark D Griffths, p. 31.

27. Michael Auer, Mark D Griffths, p. 31.

28. Michael Auer, Mark D Griffths, p. 31.

29. Travis Sztainert, Hyoun S, Michael JA Wohl (2014) Knowledge Translation and exchange in gambling research: A beginner's guide. Responsible Gambling Review 1: 64-74.
Your next submission with Juniper Publishers will reach you the below assets

- Quality Editorial service

- Swift Peer Review

- Reprints availability

- E-prints Service

- Manuscript Podcast for convenient understanding

- Global attainment for your research

- Manuscript accessibility in different formats ( Pdf, E-pub, Full Text, Audio)

- Unceasing customer service

Track the below URL for one-step submission https://juniperpublishers.com/online-submission.php 